Southwest Europe

100
75
50
25
0

औ. + -

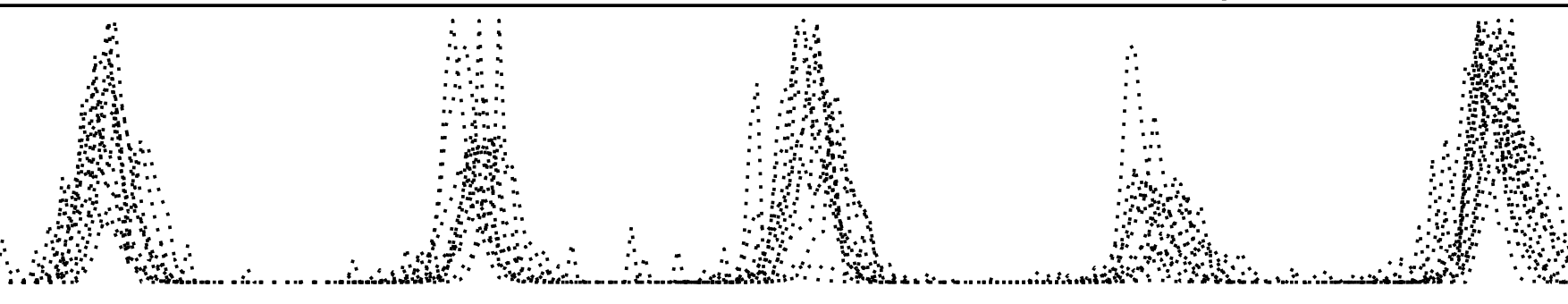

Eastern Europe

100
75
50
25
0

(2)
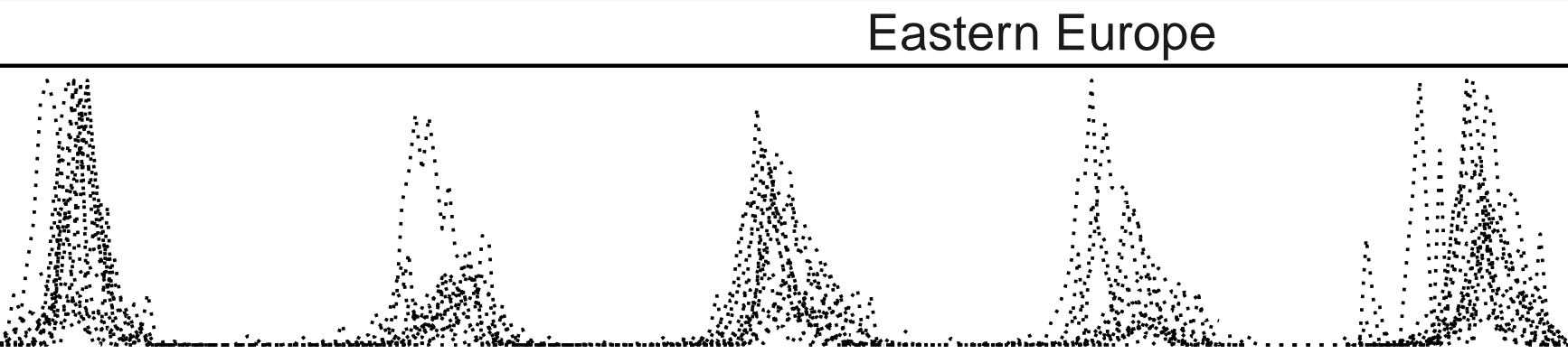

Northern Europe

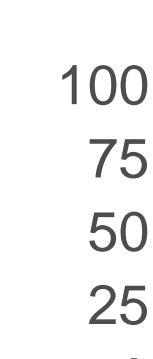

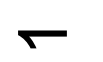

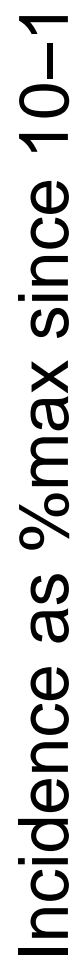

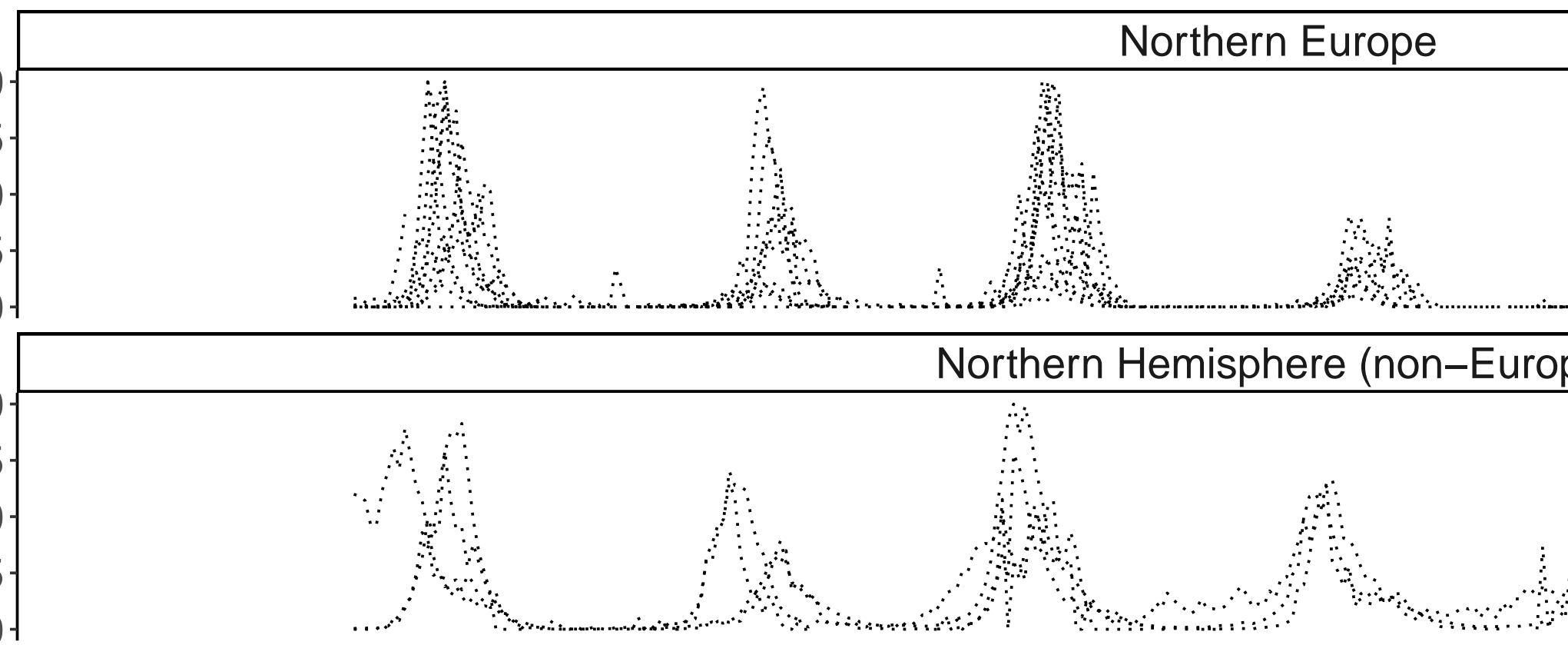

Southern Hemisphere

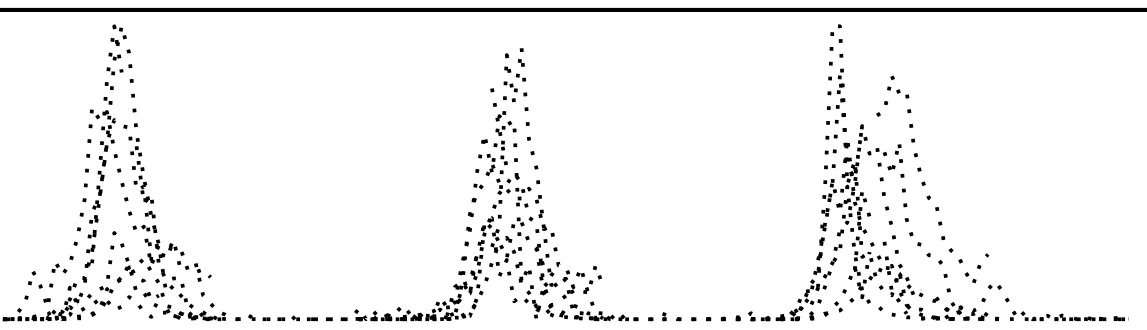

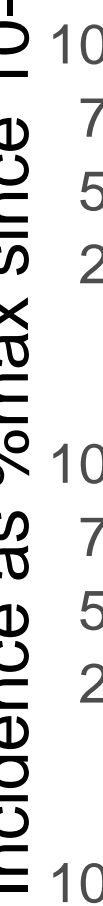

\title{
Latin America
}
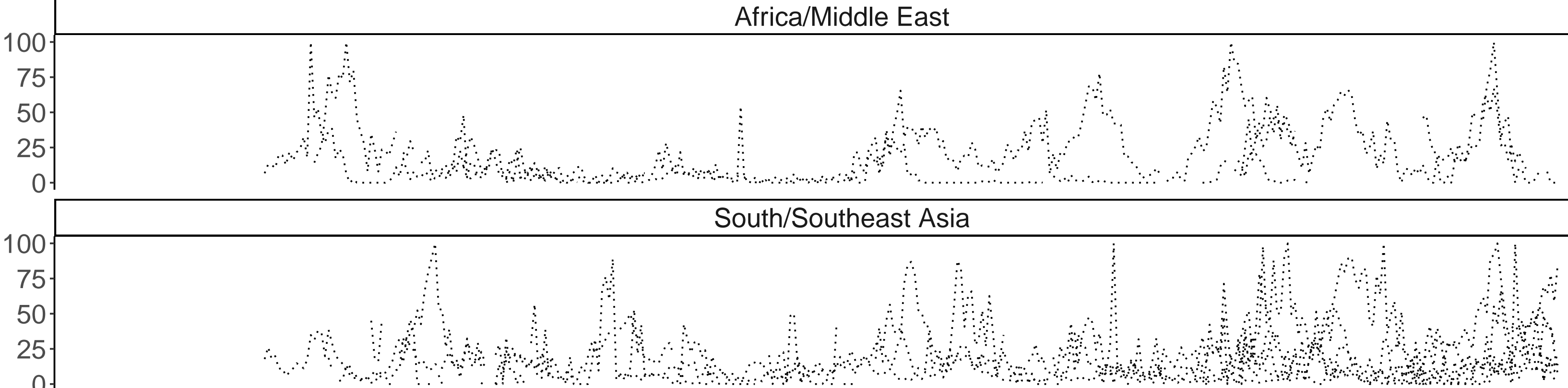

00
75
50.
25
0.

South/Southeast Asia 